\title{
THE TERMINAL ABDOMINAL STRUCTURES OF MALE DIPTERA
}

\author{
By G. C. Crampton, Ph.D. \\ Massachusetts State College, Amherst, Mass.
}

The interpretation of the structures here described, was worked out a number of years ago, in preparing the chapter on the morphology of the Diptera for the forthcoming volumes of the Diptera of Connecticut; but the publication of this work has been indefinitely postponed due to lack of funds for its publication. Since the facts brought out in this study are rather "revolutionary" and indicate that the current interpretations of the terminal structures of male Diptera should be drastically revised, it has seemed advisable to present these facts at this time instead of waiting any longer to publish them.

Many male Diptera are able to twist their terminal abdominal segments about at least temporarily, in adaptation to the different positions assumed by the males during copulation, and a permanent displacement of the parts may occur as early as the pupal stage in the Cyclorrhapha (Calliphora), or just after emerging from the pupal stage, as in the Culicidæ, certain Tipulidæ, etc.

Even such primitive Diptera as the Tanyderid Protoplasa fitchii may exhibit an inversion of the ninth abdominal segment, as is indicated by all of the males of this species which I have examined (suggesting that the rotation may be permanent, instead of a temporary adaptation during copulation), and a permanent inversion of the ninth segment (which is rotated about the long axis through 180 degrees) occurs in male Culicidæ, certain Tipulidæ, etc., among the Nematocera. Among the Brachycera, an inversion, or torsion, may occur in certain Asilidæ and Dolichopodidæ, as well as in the Bombyliidæ and Certidæ, while a similar tendency toward a torsion of the parts is exhibited by the 
Phoridæ Lonchopteridæ, etc., which occupy a border-line position between the Brachycera and the Cyclorrhapha (being placed among the Brachycera by some dipterists, while others place them in the Cyclorrhapha). A permanent torsion of the parts apparently occurs in all true Cyclorrhapha, as is indicated by a displacement of the external sclerites, spiracles, etc., and by the looping up of the ejaculatory duct, etc., over the top of the hindgut (from left to right) in all of the Cyclorrhapha I have examined (see Figs. 17 and 19 for illustrations of such a looping over of the parts in question).

In such Nematocera as the male Culicidæ, an inversion of of the ninth segment (together with the proctiger, or anusbearing segmental complex) occurs by rotating the parts (through 180 degrees) from left to right around the long axis of the body of the insect; and the designation "rotation" should be restricted to such a transverse revolving of the parts around the long axis of the insect. The resulting inversion may be termed a rotated inversion or "transinversion" to distinguish it from the next type to be considered. After an inversion of this type, the anus, genitalia, etc., still project posteriorly along the long axis of the body.

In many of the higher Diptera, on the other hand, an inversion of the ninth segment (with the proctiger) may occur by twisting it forward and around in a more vertical plane. The resulting inversion may be termed a torque inversion, or "retroinversion", to distinguish it from the type of inversion mentioned above. After an inversion of this type, the anus, etc., is usually directed forward (instead of posteriorly), as is the case in the Syrphid Heliophilus, shown in Fig. 6, and in the Pyrgotid (Ortalid) Pyrgota, shown in Fig. 3. This type of torsion usually involves the displacement of the eighth sternite, which may be accompanied by the seventh and even the sixth, abdominal sternite as it is twisted upward. The way in which the displacement and modification of the parts has been brought about in the higher Diptera may be illustrated by a series of male Diptera shown in Figures 1 to 9 , inclusive.

The Bibionid Dilophus shown in Fig. 1 may be taken as the starting point for the serries, since the condition exhibited by it is fairly typical of the Nematocera in general, in which 
the ninth segment with the proctiger, etc., extends straight back in the long axis of the body (see also the primitive Nematoceran Trichocera, shown in Fig. 14). In Dilophus (Fig. 1) the eighth sternite $8 \mathrm{~s}$ is very large, and shows no sign of displacement.

In the next stage represented by the Rhagionid (Leptid) Rhagio, shown in Fig. 2, the ninth segment is tilted upward and the conjunctivae or intersegmental membranes are very extensive, giving free play to the temporary twisting of the parts in mating. The eighth tergite $8 \mathrm{t}$ is reduced, but the eighth sternite 8s remains large, and the parts of the seventh segment are not effected by the process.

A slightly higher stage of specialization is illustrated by the Stratiomyid Ptecticus, shown in Fig. 4. In this fly the ninth segment is very large and the conjunctiva are very extensive to permit a twisting of the parts in copulation. The tergites of both the eighth and the seventh abdominal segments are reduced to narrow transverse strips, and the eighth sternite 8s shows signs of having been slightly displaced upward, at least temporarily, during the mating process (this specimen was captured in copula).

A still higher stage of specialization is illustated by the Syrphid Heliophilus shown in Fig. 6. The ninth abdominal segment remains permanently twisted forward in the torsion process, and the huge eighth sternite $8 \mathrm{~s}$, although still ventrally located, becomes slightly lateroverted, or displaced upward into the insect's left side. The eighth tergite has become atrophied, or is represented by the narrow transverse sclerite lying just behind the seventh tergite, $7 \mathrm{t}$, and anterodorsad of the eighth sternite. The seventh tergite, $7 t$, is reduced, as is also the case with the sixth and fifth abdominal tergites, $6 \mathrm{t}$, and $5 \mathrm{t}$; and their sternites exhibit indications of slight lateroversion.

Turning next to the Syrphid Chrysotaxoides, shown in Fig. 8, we note that the ninth abdominal segment, 9t, is twisted still further around (ventrally) and the huge eighth sternite, $8 \mathrm{~s}$, becomes drawn up into the dorsal region, and is almost inverted. The seventh sternite, $7 \mathrm{~s}$, follows it to some extent, and is lateroverted into the insect's left side, but the seventh tergite, $7 t$, is not greatly affected by the process, and the left spiracle of the seventh segment remains 
but slightly displaced upward. In the Syrphid Syrphus rectus shown in Fig. 17, the ninth segment faces more nearly backward as the result of the continued twisting process, and the sixth and seventh sternites, $6 \mathrm{~s}$ and $7 \mathrm{~s}$, follow the eighth sternite, $8 \mathrm{~s}$, as it becomes drawn upward. The ejaculatory dust, ed, shows through the thin integument of this Syrphid, and clearly indicates that there has been a clockwise torsion (viewing the insect from behind) of the parts, since the duct loops up over the top of the hindgut, from left to right. If there is any doubt that the sclerite $8 \mathrm{~s}$, interpreted as a sternite in these insects, is actually a sternite, rather than a tergite, it is only necessary to compare the parts with those of the Pyrgotid (Ortalid) Pyrgota undata, shown in Fig. 3, in which the huge eighth sternite, $8 \mathrm{~s}$, is only slightly lateroverted into the insect's left side, and preserves its typical relation to the seventh and sixth sternites, labelled $7 \mathrm{~s}$ and $6 \mathrm{~s}$ in Fig. 3; and if the sclerite labelled $8 \mathrm{~s}$ were a tergite, instead of a sternite, the torsion would have to take place in a counter-clockwise manner, which it does not do in any of the insects whose internal structures have been examined.

Turning next to the Coelopid Coelopa frigida shown in Fig. 5, we note that the ninth tergite, 9 t, has now completed the torsion process, and the anus faces posteriorly again, from this stage onward. The genitalia project downward, however, (instead of posteriorly as in the Nematocrea), and the aedeagus, ae, now projects anteriorly (instead of posteriorly) as in most Cyclorrhapha. This completion of the torsion process is spoken of as a "circumversion" or a reversion. The eighth sternite, $8 \mathrm{~s}$, has now become almost inverted and the asymmetrical seventh sternite, $7 \mathrm{~s}$, follows it upward into the insect's left side. The spiracle of the right side of the seventh segment has apparently become drawn down and around into the insect's left side, and the small narrow sclerite just below it appears to be the remains of a portion of the seventh tergite. The asymmetrical sixth sternite, $6 \mathrm{~s}$, is lateroverted and the right spiracle of the sixth segment is drawn down and around into the insect's left side indicating the extent of the torsion process in this region. The fifth segment is not affected by the process, in the Muscoids in general.

A further advance in the direction of the Muscoid flies is 
illustrated by the Helomyzid Neoleria crassipes shown in Fig. 7, in which the relative proportions of the segments are essentially those characteristic of the typical Muscoid flies next to be considered. The fifth segment is practically unmodified, the sixth tergite, 6t, retains its normal position, but its asymmetrically developed sternite, $6 \mathrm{~s}$, is lateroverted and becomes attached by one corner to the lateroverted seventh sternite, $7 \mathrm{~s}$, which, in turn, is attached by one corner to the inverted eighth sternite, 8s. The left spiracle of the seventh abdominal segment is displaced dorsad, but is not enclosed in the sclerites behind it.

A higher stage of specialization is illustrated by the Muscid Hylemya antiqua shown in Fig. 20, in which the parts bear essentially the same relations to each other as they do in Fig. 7, save that the seventh sternite, 7s, has now become adherent to the eighth sternite, $8 \mathrm{~s}$, from which it is demarked by an incomplete suture; and the left spiracle of the seventh segment is now borne in the anterior region of the composite sclerite made up of the lateroverted seventh sternite and the inverted eighth sternite (with which the reduced seventh tergite may also have united, although the fate of the seventh tergite cannot be definitely determined from the available material).

We may speak of the composite sclerite made up of the uniting seventh and eighth sternites (7s and $8 \mathrm{~s}$ of Fig. 20) as a synsternite, to denote the fact that it is composed of the sternites of more than one segment, although it is usually spoken of as one "segment," called the first genital "segment," while the ninth segment is then called the second genital segment. The so-called second genital segment, (or ninth abdominal segment) of the Muscoid flies is called the andrium in lower insects, while its sternite is called the hypandrium and its tergite is called the epandrium; and these terms might also be applied to the parts in Muscoid flies, in which the term protandrium might then be substituted for the designation "first genital segment," which is not a single segment but is a composite synsternite.

The slender curved sixth sternite $6 \mathrm{~s}$ of Fig. 20 supports a genital pouch, or cubiculum, in which the anteriorly directed aedeagus, ae, is received in repose, and this type of structure is typical of many Muscoidea. The fifth sternite 
labelled 5s in Fig. 20, has become cleft posteriorly to form two copulatory lobes, labelled 1 , which function in the mating process, and also project backward below the aedeagus to protect it when it is received in the genital pouch.

The Metopiid fly Phormia regina shown in Fig. 21 is typical of the Muscoidea in general, and may serve as the basis for comparing the parts in the other members of this superfamily. Its structures are essentially like those of the fly shown in Fig. 20, but the union of the seventh sternite, $7 \mathrm{~s}$, with the eighth sternite, $8 \mathrm{~s}$, is more complete, and the seventh sternite is apparently reduced to the small indistinct area labelled 7s in Fig. 21. The left spiracle of the seventh abdominal segment is borne near the anterior border of the synsternite (composite seventh and eighth sternites) in Fig. 21, but in the Muscid fly Parallelomma, in which the synsternite (or composite seventh and eighth sternites) becomes greatly enlarged along the long axis of the body, the spiracle in question is situated far back in the enlarged synsternite, which may indicate that the seventh sternite, which contributes to the formation of the synsternite, is of considerable extent. On the other hand, in another Muscid fly Musca domestica, in which the synsternite is reduced to a narrow transverse sclerite, the left spiracle of the seventh segment remains far down toward the anterior margin of the synsternite, indicating that the seventh sternite forms a relatively unimportant portion of the reduced synsternite.

In Musca domestica a further specialization is indicated by the fact that the sixth abdominal sternite (which exhibits a tendency to attach itself to the synsternite labelled $7 \mathrm{~s}$ and 8s in Fig. 21) migrates from its position below the sixth tergite, and becomes so closely associated with the ventral region of the narrow transverse synsternite that it appears to be the sternite of a segment whose tergite is represented by the narrow transverse synsternite; and it is small wonder that these structures have been misinterpreted in Musca domestica, although a comparison of the parts with those of the Muscoid fly shown in Fig. 21 (and tracing the parts on back through the series here described) would readily reveal the true homologies of the parts in the housefly.

The modificational trends exhibited by the series of flies shown in Figs 5, 7, 20 and 21, indicate a rather close relation- 
ship between the members of this series, but the modifications exhibited by such a fly as the one shown in Fig. 22, in which the sixth segment remains unaffected by the lateroversion of the seventh sternite 7s (and by the inversion of the eighth sternite 8s) would indicate that Calobata is a member of a series quite different from that to which the above mentioned flies belong, and the trends exhibited by these flies should be of considerable value for arranging them according to their natural affinities, although I do not know of any attempt to utilize the sclerites of this region of the body for such a purpose.

In this connection it may be remarked that the modificational trends exhibited by a Dolichopodid fly such as Argyra (shown in Fig. 23) seem to foreshadow many of the modifications later occurring in certain Cyclorrapha, just as the antennæ of certain Dolichopodidæ approach those of the typical Cyclorrhapha, and these facts may indicate that the Dolichopodidæ are much nearer to the ancestors of the Cyclorrhapha than is commonly supposed to be the case.

In like manner, the modificational trends exhibited by such Syrphidæ as Paragus (shown in Fig. 9) seem to foreshadow the modifications later occurring in certain higher Cyclorrhapha. Thus the lateroverted seventh sternite, 7s, unites with the inverted eighth sternite, 8s, in Paragus (Fig. 9) as it does in Hylemya (Fig. 20), for example. The sixth sternite, $6 \mathrm{~s}$, is asymmetrical and is strongly lateroverted in Paragus (Fig. 9), as it is in Hylemya (Fig. 20compare also Fig. 7), and the fifth sternite labelled $5 \mathrm{~s}$ in Fig. 9 of Paragus is deeply emarginated posteriorly, dividing the fifth sternite into widely separated parts which suggest the origin of the condition exhibited by Hylemya (Fig. 20 ), in which a deep posterior cleft divides the fifth sternite into the posteriorly projecting copulatory lobes labelled 1 in Fig. 20. These and many other facts suggest that the Syrphidæ represent the ancestors of certain other Cyclorrhapha as nearly as any known forms; and the Syrphidæ furnish the most useful clues for determining the homologies of the genital structures of the higher Cyclorrhapha, as will be shown later.

Before discussing the homologies of the genital forceps of the lower Diptera a brief statement may be made concerning 
the nature of the parameres of male Coleoptera and $\mathrm{Hy}$ menoptera, which represent the starting point for the derivation of the genital forceps of male Mecoptera, Trichoptera, Diptera, etc. Since the Coleoptera are more "orthopteroid" than the Hymenoptera, the condition exhibited by their genital structures should be more primitive, or ancestral, than is the case with the parts in the Hymenoptera, and the Hymenopterous type was probably derived from the more primitive Coleopterous type of genitalia occurring in such primitive Coleoptera as the Lampyridæ. In males of the common Lampyrid beetle Lucidota corrusca, the unsegmented parameres are borne on a broad basal ring corresponding to the narrower basal ring labelled ge in Fig. 11 of the primitive Hymenopteron Xyela (so that this type of basal ring is not peculiar to the Hymenoptera alone, as is commonly thought to be the case) in which the basal ring bears a pair of segmented forceps occupying exactly the same position (on each side of the median aedeagus) that the unsegmented parameres do in Lucidota. It is therefore evident that the unsegmented parameres of the more primitive Coleoptera merely become secondarily divided into a basal and distal segment in the Hymenoptera, although Snodgrass, 1941 (Smithsonian Misc. Collections, Vol. 99, No. 14) considers that the parameres of the Hymenoptera are represented by only the distal segments of the forceps. In the following discussion the basal segment of the forceps will be referred to as the basimere or basistyle ( $b$ of Figs. 11 to 13) and the distal segment of the forceps will be termed the distimere or dististyle (d of Figs. 11 to 13).

In the Bulletin of the Brooklyn Entomological Society for 1938, Vol. 33, page 3, the writer first called attention to the fact that in male Mecoptera Diptera, etc., the basimeres (b of Figs. 12 and 13) do not represent abdominal coxites, and the distimeres (d of Figs. 12 and 13) do not represent styli, as is commonly supposed to be the case, but these segments of the genital forceps of the Mecoptera, Trichoptera, Diptera, etc., are clearly homologous with the segments labelled $b$ and $d$ of the parameres of such a Hymenopteron as that shown in Fig. 11; and it is difficult to understand how anyone could examine such a series of genital forceps as that shown in Figs. 11, 12 and 13, without immediately 
realizing this fact, if comparative morphology has any meaning at all. The only baffling difficulty presented by the parts in these insects is the question as to the homology of the basal area bearing the label $\mathrm{g}$ in Fig. 13, which may represent either the basal ring gc of Fig. 11, or it may represent the remains of the ninth sternite which unites with the basimeres of the forceps, or it may represent a secondarily demarked area in the basal region of the uniting basimeres of the forceps, and the latter explanation seems as logical as any.

The ninth sternite is separated from the basal segments of the genital forceps in the Trichoceridæ (Fig. 14), as is also the case in such Tipulidæ as Macrocera, etc., but in the genus Tipula the ninth sternite tends to unite with the basal segments of the genital forceps, and this tendency is carried still further in many other Diptera. In the primitive Dipteron Protoplasa fitchii shown in Fig. 15, the ninth sternite 9s apparently becomes greatly reduced before it unites with the basal segments of the forceps, and the condition exhibited by Protoplasa suggests that the area labelled $\mathrm{g}$ in Fig. 13 may also represent such a reduced ninth sternite which has united with the basal segments of the forceps, although it is also possible that the area labelled $g$ in Fig. 13 is comparable to the region between the bases of the genital forceps in the Trichoceridæ (Fig. 14), and a third possibility is that both the area labelled $\mathrm{g}$ in Fig. 13, and that interpreted as the reduced ninth sternite in Fig. 15 $(9 \mathrm{~s})$, may represent the basal ring of the genital forceps of the Hymenopteron Xyela (Fig. 11, gc).

The distal segments of the forceps, labelled d in Fig. 15 of Protoplasa, are forked, and if the cleft of the fork were deepened basad, it would eventually divide the distal segment into an inner and outer distimere (or dististyle) like those labelled id and od in Fig. 10 of the Tipulid Acantholimnophila; and it is very probable that the outer and inner distimeres or dististyles characteristic of most Tipulidæ arose from such a longitudinal splitting of the distimeres.

The basal segments of the genital forceps of Acantholimnophila bear slender mesal processes called interbases (labelled ib in Fig. 10) ; and the ninth tergite, 9t, of Fig. 10, bears a pair of posterior lobes in this insect, which may cor- 
respond to the processes of the ninth tergite labelled st in Fig. 15 of Protoplasa, and these in turn may correspond to the long slender processes of the ninth tergite labelled st in Fig. 16 of the Ptychopterid Bittacomorpha. It is probable that such processes of the ninth tergite of the lower Nematocera become the articulated processes of the ninth tergite called surstyli, or edita, in such Cyclorrhapha as those shown in Figs. 8, 9, 20 and 21, etc., in which the surstyli are labelled st.

The proctiger, or anus-bearing region behind the ninth tergite, labelled $9 t$ in Figs. 1, 2, 4, 5, 8, etc., is apparently composed of the greatly reduced tenth abdominal segment, with which the similarly reduced, cerci-bearing, eleventh abdominal segment, and the anus-bearing telson, have united. The structures labelled ce in these figures are interpreted as true cerci since they are clearly homologous with the cerci of female Tipulidæ and female Mecoptera, etc., in which the structures in question are borne on a distinct, though greatly reduced, eleventh abdominal segment, as is the case with the cerci of lower insects, in which the cerci are appendages of the eleventh abdominal segment.

In attempting to determine what genital structures of the higher Diptera shown in Figs. 19, 20, 21, etc., correspond to the segments of the genital forceps of the lower Diptera, such as those shown in Figs. 1, 2, 3, etc., it is necessary first to compare them with the parts in the key group Syrphidæ (Fig. 17) which occupies a position intermediate between the higher and the lower Diptera, and furnishes the necessary clues for tracing the modifications met with in the sclerites and other structures of the higher forms.

Starting with the lower Nematocera, in which the segments of the genital forceps $b$ and $d$ are long and slender, as they are in the Nematocera shown in Figs. 14, 15, etc., we note that the segments tend to become shorter and stouter in the genital forceps of the Brachycera shown in Figs. 2 and 4 ; and in the Stratiomyid Ptecticus shown in Fig. 4, the distimeres, labelled $d$, are broad and flat, like the distimeres labelled d in Fig. 17 of the Syrphid Syrphus rectus, while the basimeres labelled b in Fig. 4 of Ptecticus, are reduced and unite with the ninth sternite, as the basimeres, $b$, do in the Syrphid shown in Fig. 17. It is thus an easy matter 
to identify the parts of the Syrphid shown in Fig. 17 with those of the lower Diptera, and it is then comparatively easy to identify the structures of the higher Diptera which correspond to the parts in this Syrphid.

In the Muscid fly Hylemya shown in Fig. 20, the structures which occupy a position on each side of the base of the aedeagus, ae, comparable to the parts situated on each side of the base of the aedeagus, ae, of the Syrphid shown in Fig. 17, are the so-called anterior and posterior "gonapophyses" (b and d) of Fig. 20, and unless these so-called "gonapophyses" are structers peculiar to the higher Cyclorrhapha, having no relation to the structures of the lower Cyclorrhapha, it is possible that these structures labelled $b$ and $d$ in the higher Cyclorrhapha shown in Figs. 20,21 , etc., may represent the basimeres, $b$, and the distimeres, d, of the primitive Cyclorrhaphan, Syrphus, shown in Fig. 17.' In the same way, the appendages, st, of the ninth tergite, $9 t$, and the lobes, ce, on each side of the anal opening of the higher Cyclorrhapha shown in Figs. 19, 21 , etc., may be identified with the surstyli, st, borne on the ninth tergite, 9t, and the cerci, ce, situated on each side of the anal opening, of the Syrphid shown in Fig. 17, and it is thus an easy matter to homologize the structures of the higher Cyclorrhapha by comparing them with the structures of the key group Syrphidæ.

With regard to the minuter details of the genital structures of the higher Diptera, it may be remarked that Lowne, 1895, in the second volume of his monumental work on the blowfly Calliphora, designates the slender structure labelled p in Fig. 21 of Phormia regina as the paraphallus, and calls the structure labelled $\mathrm{h}$ in Fig. 21 the hypophallus. The genital spine labelled e in Figs. 19 and 21, etc., is usually called the epiphallus, and the basal and distal portions of aedeagus ae, labelled a and ph in Fig. 21 have been called the phallophore and phallus.

Of the internal structures in this region, mention may be made of the phallic apodeme, pa, of Figs. 19 and 21, which

1It is preferable to refer to the structures labelled $b$ and $d$ in Figs. 19, 20 and 21 , of the higher Cyclorrhapha, simply as the anterior and posterior gonapophyses until their homologies have been definitely determined. 
operates the parts in the basal region of the aedeagus, and the hypandrial apodeme, ha, of Figs. 19 and 21, which is formed by an internal inflexion of the ninth sternite or hypandrium, $9 \mathrm{~s}$, for the attachment of muscles moving these structures. Lowne, 1895, designates the structures labelled pg in Fig. 19, as the paragonia (they have been called seminal vesicles by other writers) and states that the secretions of these structures coagulates in the ejaculatory duct, or in the vagina of the female, to form a type of spermatophore. The seminal fluid is ejaculated through the action of the ejaculator em of Fig. 19, which functions as a syringe to force the fluid out through the aedeagus when the muscles attached to the sclerite in its membranous walls, etc. contract.

The interpretations given the different structures here discussed are the same as those proposed six years ago in a short paper published in the Bulletin of the Brooklyn Entomological Society for 1936, Vol. 33, No. 4, p. 141. This earlier paper, however, was apparently too brief and the accompanying figures were too few, to carry any conviction for those who have published on the morphology of the Mecoptera, Diptera, etc., since that time, so that no consideration has been given by recent investigators to the views set forth in this previous paper. It is to be hoped, however, that a re-statement of these views, illustrated by a wide series of intermediate forms indicating the steps in the development of the structures of the higher Diptera, will cause other investigators to take these views into consideration, since the conclusions here drawn are based upon an extensive study of a wide range of Dipterous types, and the clear cut evolutionary trends here described must be explained in some other way if the interpretations here suggested are not accepted. 


\section{List of AbBreviations}

a........ Phallophore

æ........ Edeagus

b....... Basimere or basistyle (basal segment of forcipate parameres), also anterior gonapophysis.

ce....... Cerci

d....... Distimere or dististyle (distal segment of parameres), also posterior gonapophysis.

e......... Genital spine or epiphallus

ed....... Ejaculatory duct

em..... Ejaculator or ejaculatory syringe

g........ Area of united basimeres of genital forceps (9th. Sternite?)

gc...... Basal ring of forceps (gonocardo)

h........ Hypophallus

ha...... Hypandrial apodeme

ib....... Interbases

id....... Inner distimere or dististyle

1........ Copulatory lobes of fifth sternite

od...... Outer distimere or dististyle

p........ Paraphalli

pa...... Phallic apodeme, or aedeagal apodeme.

pg...... Paragonia

ph...... Phallus

ps...... Phallosome

r......... Rectal papillæ

s......... Sternites

st....... Surstyli or edita

t......... Tergites

ts....... Testes 


\section{Explanation of Plate VII}

Fig. 1......Lateral view of terminalia of Dilophus (Bibionidæ).

Fig. 2......Lateral view of terminalia of Rhagio vertebratus (Rhagionidæ)

Fig. 3......Lateral view of terminalia of Pyrgota undata (Pyrgotidæ)

Fig. 4.......Lateral view of terminalia of Ptecticus (Stratiomyidæ)

Fig. 5.......Lateral view of terminalia of Colopa frigida (Coelopidæ)

Fig. 6......Lateral view of terminalia of Heliophilus chaligosa (Syrphidæ)

Fig. 7......Lateral view of terminalia of Neoleria crassipes (Helomyzidæ)

Fig. 8......Lateral view of terminalia of Sericomyia chrysotaxoides (Syrphidæ)

Fig. 9......Lateral view of terminalia of Paragus bicolor (Syrphidæ)

\section{Explanation of Plate VIII}

Fig. 10....Dorsal view of genital forceps of Acantholimnophila maorica (Tipulidæ)

Fig. 11.... Ventral view of genital forceps of Xyela (Tenthredinidæ)

Fig. 12....Ventral view of genital forceps of Tæxiochorista pallata (Panorpidæ)

Fig. 13....Ventral view of genital forceps of Rhagio (Rhagionidæ)

Fig. 14....Lateral view of terminalia of Trichocera (Trichoceridæ)

Fig. 15....Lateral view of terminalia of Protoplasa fitchii (Tanyderidæ)

Fig. 16....Lateral view of terminalia of Bittacomorpha (Ptychopteridæ)

Fig. 17....Ventral view of terminalia of Syrphus rectus (Syrphidæ)

Fig. 18....Ventral view of terminalia of Mesograpta marginata (Syrphidæ)

Fig. 19....Lateral view of internal genital apparatus of Phormia regina (Metopiidæ)

Fig. 20....Lateral view of terminalia of Hylemya antiqua (Muscidæ)

Fig. 21....Lateral view of terminalia of Phormia regina (Metopiidæ)

Fig. 22....Lateral view of terminalia of Calobata pallipes (Colabatidæ)

Fig. 23....Lateral view of terminalia of Argyra (Dolichopodidæ) 


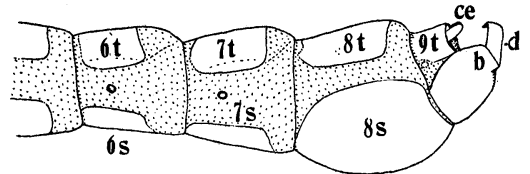

Fig. 1
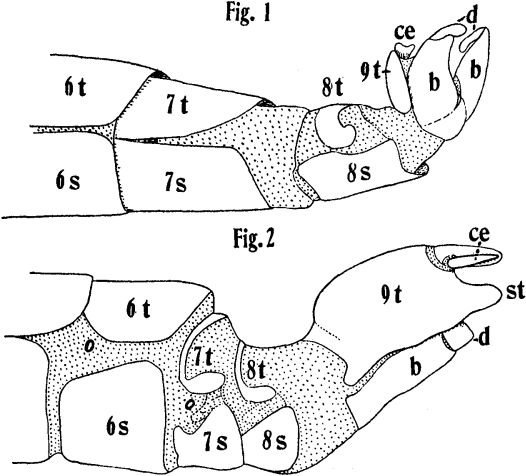

Fig. 4

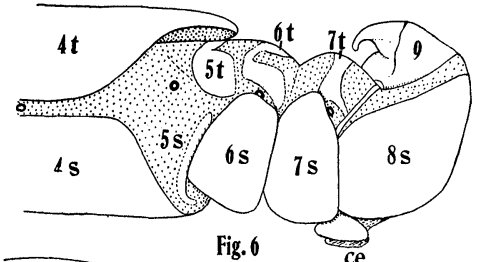

Fig. 6 ce

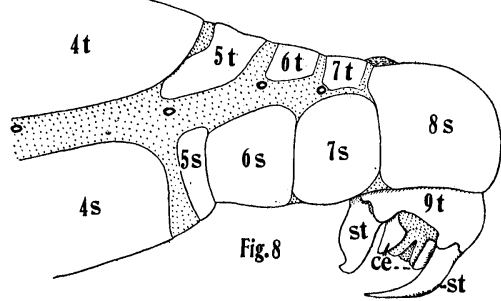

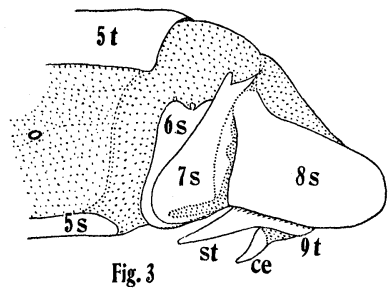

Fig. 3
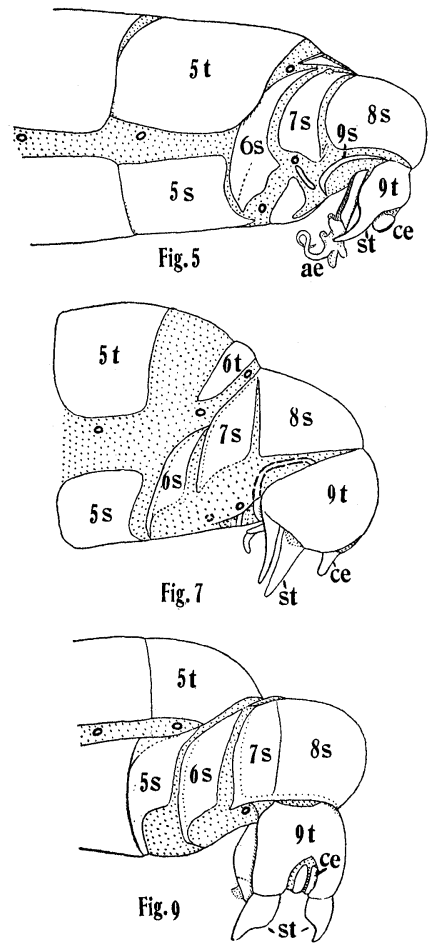


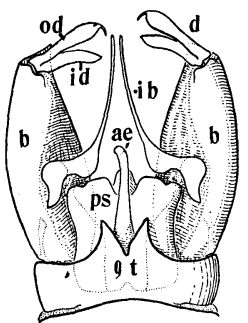

Fig. 10

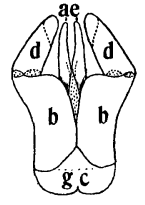

Fig. 11

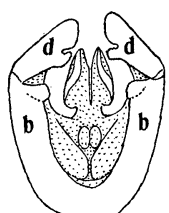

Fig. 12

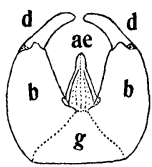

Fig. 13

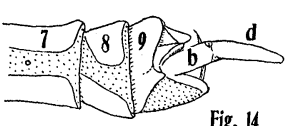

Fig. 14

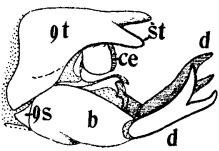

Fig. 15
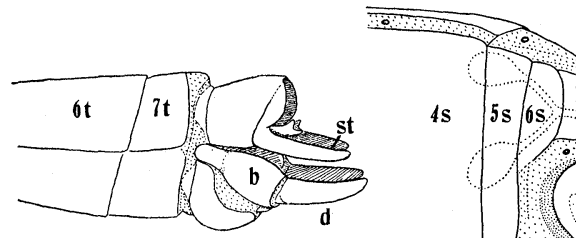

Fig. 16

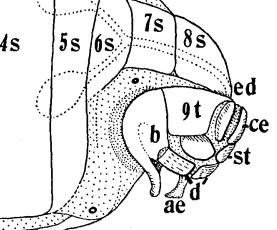

Fig. 17
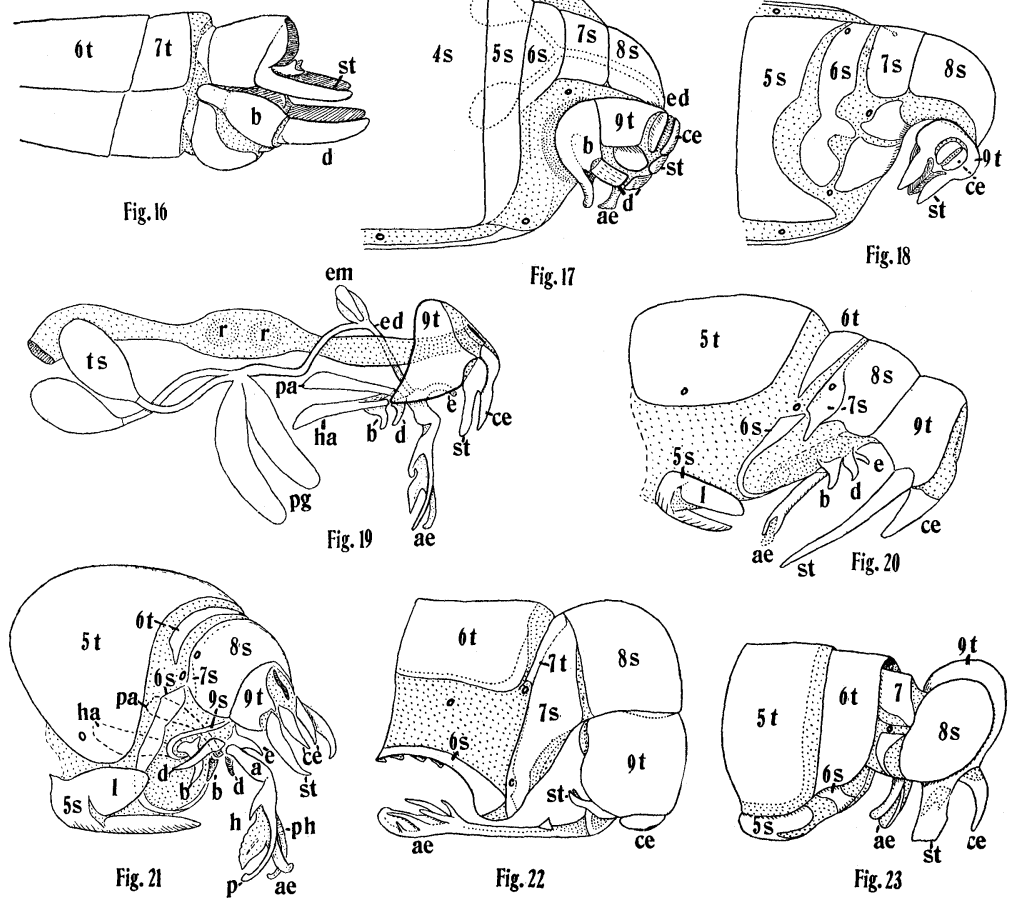

Fig. 23

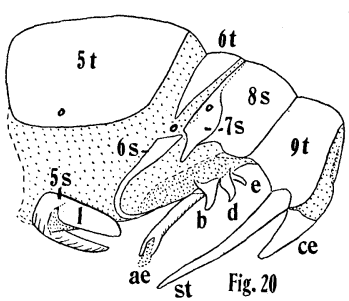



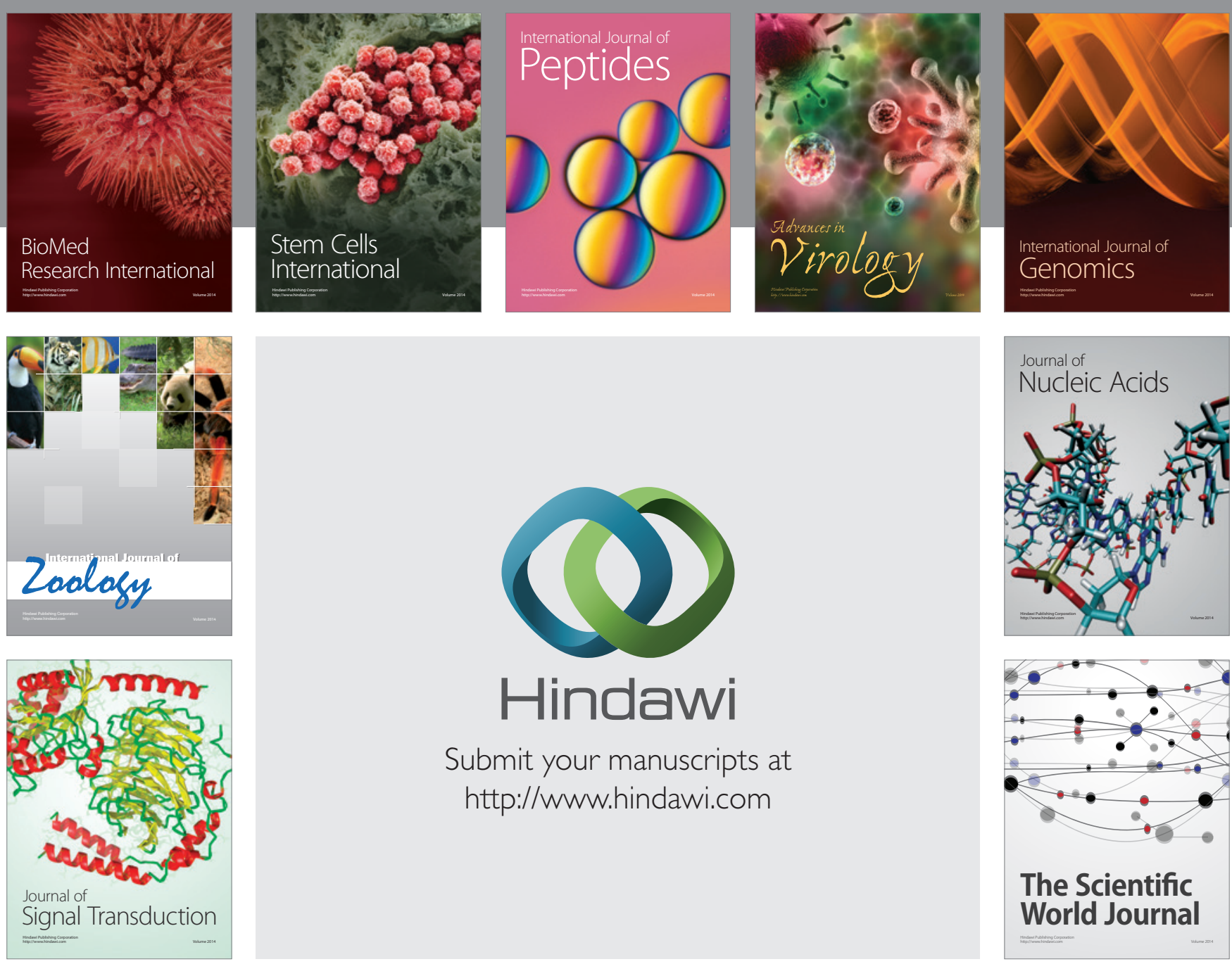

Submit your manuscripts at

http://www.hindawi.com
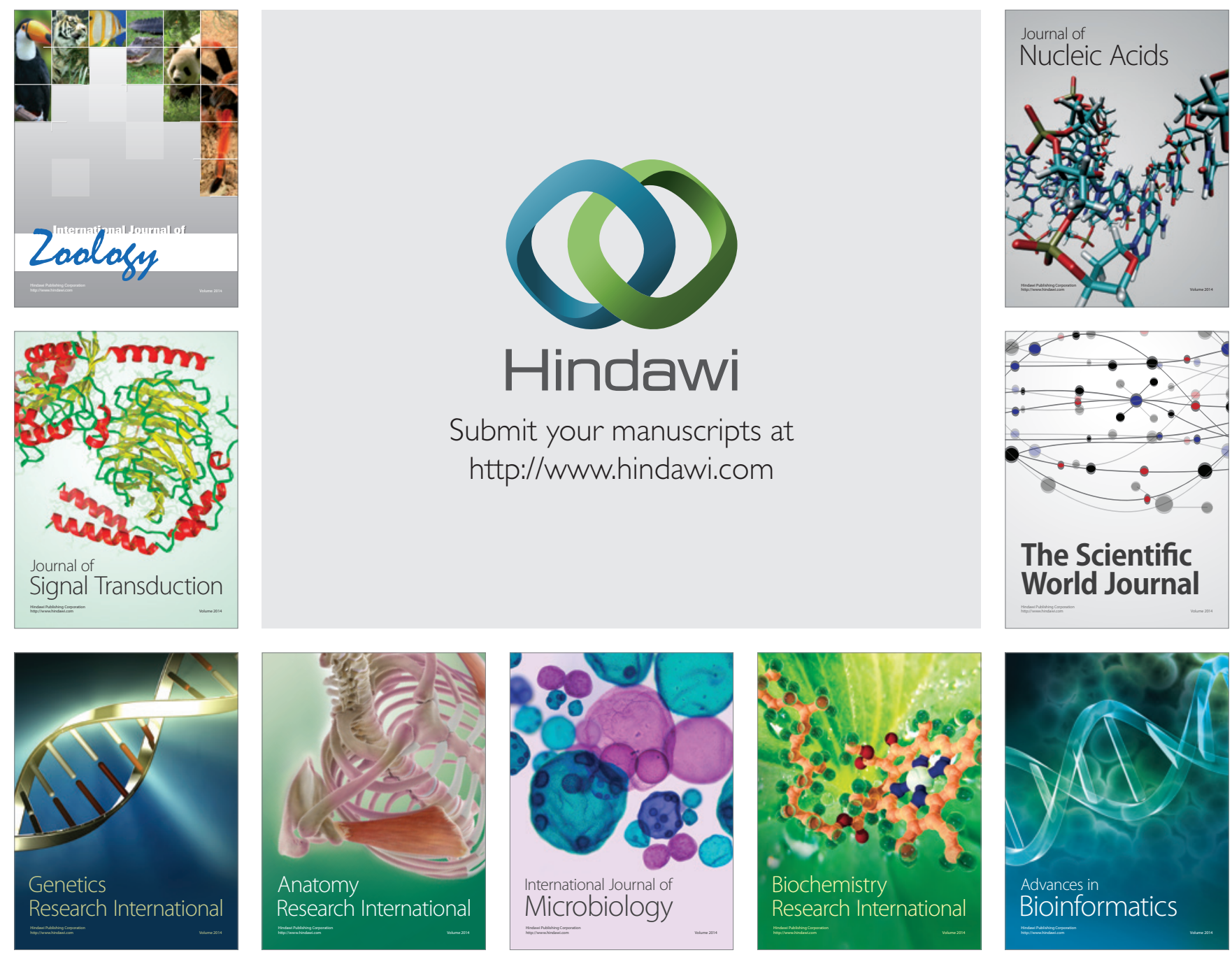

The Scientific World Journal
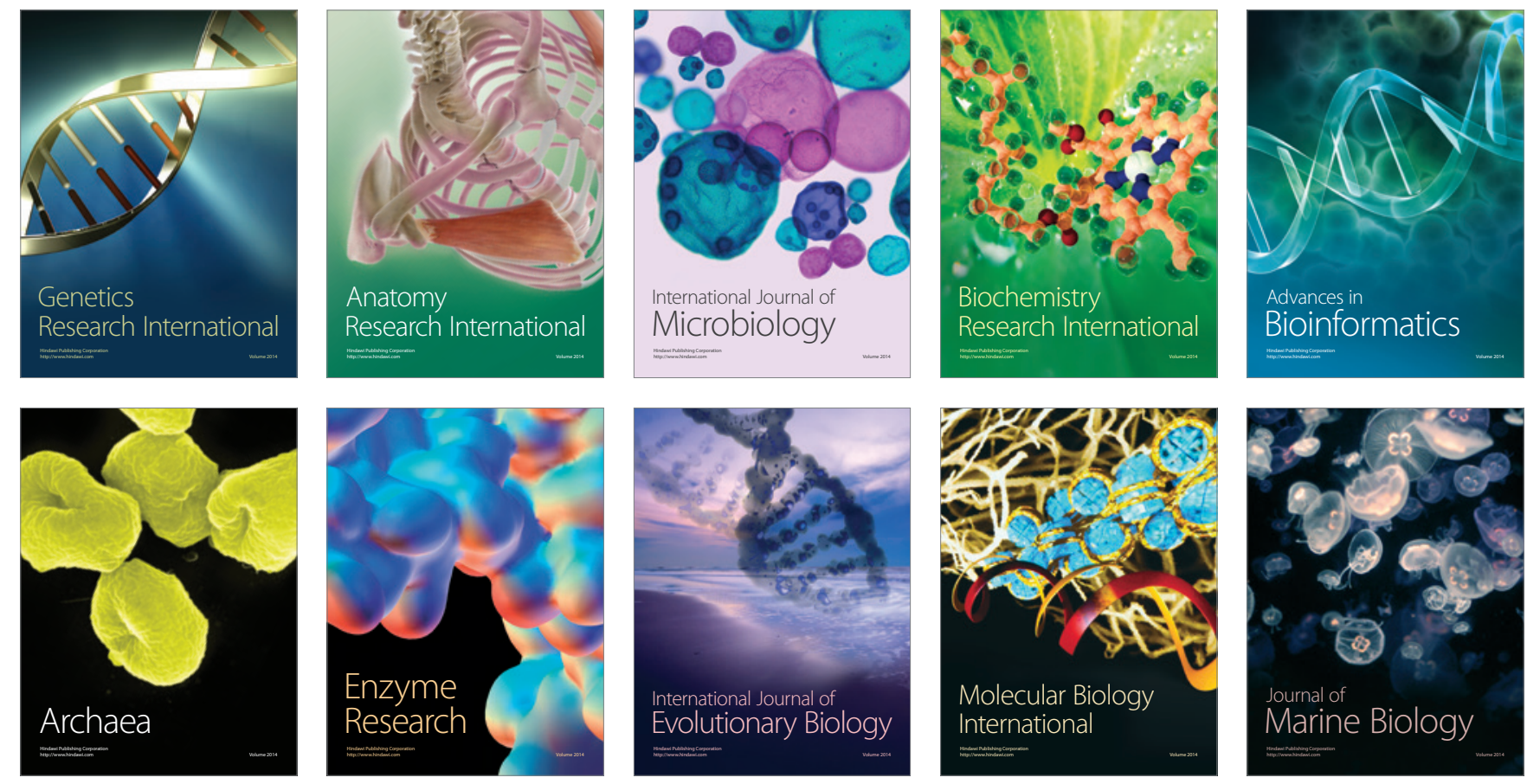